\title{
Oral Solution/Concentrate for Nebulizer Solution
}

National Cancer Institute

\section{Source}

National Cancer Institute. Oral Solution/Concentrate for Nebulizer Solution. NCI

Thesaurus. Code C149722.

Liquid preparation consisting of a solution intended for oral use or intended to be diluted in the specified liquid to obtain a nebulizer solution. 